\title{
Associations of Education with Blood Pressure in Hypertensive Patients: A Chinese Community Survey
}

\author{
Xiaojun Chen, Xuerui Tan ${ }^{*}$ \\ Department of Cardiovascular Diseases, The First Affiliated Hospital of Shantou University Medical College, Shantou, China \\ Email: ${ }^{*}$ tanxuerui@vip.sina.com
}

Received June 7, 2013; revised July 16, 2013; accepted August 2, 2013

Copyright (C) 2013 Xiaojun Chen, Xuerui Tan. This is an open access article distributed under the Creative Commons Attribution License, which permits unrestricted use, distribution, and reproduction in any medium, provided the original work is properly cited.

\begin{abstract}
Objective: To examine the association between education and blood pressure in hypertensive Chinese. Methods: A cross-sectional study was conducted at the health care center of a university affiliated hospital in 2008 to enroll 502 mild to moderate essential hypertensive patients. All participants completed a questionnaire addressing their sociodemographic information before they were given a routine physical check-up. Results: The baseline blood pressure was $151.87 / 95.76 \mathrm{mmHg}$ for 277 females and $149.80 / 97.74 \mathrm{mmHg}$ for 225 males. Only few women reported smoke $(4 \%, \mathrm{n}$ $=11)$ or drink alcohol $(6.9 \%, \mathrm{n}=19)$. Over half of men smoke and drink (63.2\% and $52.9 \%$ respectively). Alcohol consumption was found different among educational attainment groups in males. Correlation analyses demonstrated that education was inversely related to systolic blood pressure in female hypertensives. Conclusion: Education is associated with blood pressure in females.
\end{abstract}

Keywords: Education; Blood Pressure; Hypertension; Survey

\section{Introduction}

Incidence of cardiovascular disease was consistently inversely associated with education and other measures of socioeconomic position, such as occupation and income [1]. As a major risk factor for cardiovascular disease, blood pressure was often analyzed to be related with improper daily habits [2]. As for relation to socio-economic status measure, elevated blood pressure has also been explored but only in white and black people and there was a slight inconsistence in the result $[3,4]$. The applicability of their findings was uncertain to other races/ ethnicities. The objective of this study was to explore the association between educational attainment and blood pressure in Orientals.

\section{Methods}

\subsection{Study Sample}

A cross-sectional survey was conducted from year 2007 to 2008 in Shantou city, Eastern China. The study population was a random cluster sample from individuals for annual physical examination in the hospital health care center. Finally 502 eligible participants with mild to

${ }^{*}$ Corresponding author. moderate essential hypertension out of 4020 individuals were recruited, as their 3 consecutive sitting diastolic blood pressure $\geq 90$ and $<110 \mathrm{mmHg}$ and/or sitting systolic blood pressure $\geq 140$ and $<180 \mathrm{mmHg}$, coinciding with WHO/ISH Hypertension guidelines. The collection of clinical and sociodemographic data and answers of the questionnaires were carried out on an individual basis by the same researcher and took approximately twenty minutes.

\subsection{Education}

Education level was one item of the questionnaire mentioned above. The participants' education was recorded into 3 categories: $\leq 6$ years (reflecting primary school or less), 7 - 12 years (indicative of high school or less including technical school) and $\geq 13$ year's education (those with more than an undergraduate college degree).

\subsection{Blood Pressure}

Enroll participants were asked to stop anti-hypertensive medication for $24 \mathrm{~h}$ before investigation. Blood pressure was measured after a 5 -minute rest in a seated position with a mercury sphygmomanometer on 3 separate visits in the morning. The average of these readings was used for analyses. 


\subsection{Covariates}

Covariates were collected by self-report at each questionnaire. Daily habits of alcohol consumption and cigarette smoking were classified as never, moderate or heavy. We defined moderate smoking as fewer than 5 cigarettes/day and heavy smoking as 20 or more cigarettes/day [5]. We categorized participants as moderate or heavy alcohol consumption if his or her intake of total alcohol of beer, wine was less than $20 \mathrm{~g} /$ day and more than $20 \mathrm{~g} /$ day respectively [6]. Occupational status was self-reported and categorized as unemployment, intellectuals work and physical labor work. Body mass index (BMI) was calculated as the weight in kilograms divided by the square of the height in meters $\left(\mathrm{kg} / \mathrm{m}^{2}\right)$. Current antihypertensive medication use was self-reported and modeled as a binary variable (yes/no).

\subsection{Statistical Analysis}

The data collected were processed and analyzed by using routine statistical methods and a $P<0.05$ level was taken to indicate the significant difference. Measures of association were analyzed by correlation analysis. All the statistics was performed by using the SPSS version 15.0.

\section{Results}

The baseline blood pressure of 277 hypertensive females was $151.87 \pm 10.13 \mathrm{mmHg}$ for SBP and 95.76 \pm 8.04 $\mathrm{mmHg}$ for DBP. The baseline blood pressure of 225 hypertensive males was $149.80 \pm 11.13 \mathrm{mmHg}$ for SBP $97.74 \pm 8.43 \mathrm{mmHg}$ for DBP. Only few women reported smoke $(4 \%, n=11)$ or drink alcohol $(6.9 \%, n=19)$. Over half of men smoke and drink (63.2\% and 52.9\% respectively). Alcohol consumption was found different among educational attainment groups in males. There was no difference between 3 educational attainment groups in SBP, DBP, anti-hypertension medication, BMI index and smoking either for female or male groups (Table 1). In females, correlation analyses demonstrated that education was inversely associated with baseline values of SBP (Table 2); in males, education was inversely associated with age only. Education level was significantly associated with occupational position. The fewer educational years, the more low occupation status reported.

\section{Discussion}

Elevated blood pressure has been demonstrated in crosssectional studies to be associated with low education and lower levels of other socio-economic status measures [7]. Several large scale epidemiological studies have been done in different races/ethnicities and there was a slight inconsistence in the result. The recent research, Framingham Offspring Study was one of the few studies in- vestigating longitudinal blood pressure trajectories over a substantial proportion of life course, have showed fairly robust inverse association with SBP and DBP in female than in male white participants [3]. This association was weaker in black participants as Strand and his colleagues had demonstrated that education was inversely associated with increases over time in SBP in males and females [4].

However, little is known about sex-specific associations between education and blood pressure and the effects of using antihypertensive medications, BMI, alcohol consumption, smoking or other potential mechanisms in Asian people. Findings in this paper demonstrated that education was inversely associated with mean SBP in female hypertensives. It suggests that low education may have an impact on blood pressure in females. Associations of education with DBP were not yet detected for both females and males. Conventional risk factors including antihypertensive medication, smoking, BMI and alcohol consumption were not related with educational attainment, neither exerting an effect on association between blood pressure and education.

Previous research in Western countries have resort individuals of low education to high strain jobs, characterized by high demand and low control, which have been associated with elevated blood pressure [8]. Other related mechanisms involve stress induced sympathetic nervous system activation due to stressful conditions outside of work were also associated with low educational attainment. These may be particularly important for women. Women with low education may have higher possibility of poor health, single-parenting, depression, income below the poverty threshold, and unemployment, compared to men with low education [9]. It could be the same with Asian women. In this study, women who received only primary school education were basically in low level occupational status $(92.8 \%)$ compared to those had college education $(40 \%)$. Research has found that education reduces the probability of unhealthy behavior over the life course [10], while healthy lifestyle factors reduced the risk of hypertension remarkably. Low socioeconomic position may be a stronger determinant of hypertension risk in women compared with men. Further, SBP tends to increase steadily with age, while DBP tends to increase until age 50 years [11], therefore, the DBP was not yet detected to be related.

However, there remained plausible as childhood socioeconomic circumstances are associated with adulthood education and blood pressure [12], parental blood pressure may be associated with offspring education and blood pressure [13]. With regard to weaknesses, the research sample of our study was relatively small as the subjects were enrolled in a Chinese community, however, the trend of association could be found out though it was 
Table 1. Characteristics of participants in cross-sectional study according to educational attainments.

\begin{tabular}{|c|c|c|c|c|c|}
\hline & \multicolumn{5}{|c|}{ Educational Attainment (years) } \\
\hline & Participants & $\leq 6$ & $7-12$ & $\geq 13$ & $P$ \\
\hline \multicolumn{6}{|l|}{ Female } \\
\hline $\mathrm{N}$ & 277 & 139 & 123 & 15 & \\
\hline Age (years) & $49.35 \pm 6.69$ & $49.81 \pm 6.91$ & $49.11 \pm 6.32$ & $47.07 \pm 7.45$ & 0.27 \\
\hline Systolic Blood Pressure, mmHg & $151.87 \pm 10.13$ & $153.32 \pm 11.59$ & $150.70 \pm 11.93$ & $148.07 \pm 7.06$ & 0.10 \\
\hline Diastolic Blood Pressure, $\mathrm{mmHg}$ & $95.76 \pm 8.04$ & $95.76 \pm 8.04$ & $95.99 \pm 8.42$ & $93.27 \pm 5.78$ & 0.46 \\
\hline Anti-Hypertensive Medication, \% & $86(31)$ & $40(46.5)$ & $42(48.8)$ & $4(4.7)$ & 0.60 \\
\hline Body Mass Index, $\mathrm{kg} / \mathrm{m}^{2}$ & $25.58 \pm 3.16$ & $25.58 \pm 3.33$ & $25.63 \pm 2.98$ & $25.18 \pm 3.16$ & 0.87 \\
\hline Smoker, \% & $11(4.0)$ & $8(72.7)$ & $3(27.3)$ & 0 & 0.63 \\
\hline Alcohol Consumption, \% & 19(6.9) & $7(36.9)$ & $11(57.8)$ & $1(5.3)$ & 0.39 \\
\hline Low Occupational Position & $218(78.7)$ & $129(59.2)$ & $83(38.1)$ & $6(2.7)$ & 0.00 \\
\hline \multicolumn{6}{|l|}{ Male } \\
\hline $\mathrm{N}$ & 225 & 34 & 149 & 42 & \\
\hline Age (years) & $49.16 \pm 7.55$ & $51.97 \pm 6.58$ & $48.81 \pm 7.17$ & $48.10 \pm 7.07$ & 0.05 \\
\hline Systolic Blood Pressure, mmHg & $149.80 \pm 11.13$ & $152.26 \pm 12.17$ & $149.64 \pm 11.35$ & $148.38 \pm 10.74$ & 0.37 \\
\hline Diastolic Blood Pressure, mmHg & $97.74 \pm 8.43$ & $97.59 \pm 8.55$ & $97.73 \pm 8.39$ & $97.90 \pm 8.66$ & 0.98 \\
\hline Anti-Hypertensive Medication, $\%$ & $82(36.4)$ & $8(9.7)$ & $55(67.1)$ & $19(23.2)$ & 0.14 \\
\hline Body Mass Index, $\mathrm{kg} / \mathrm{m}^{2}$ & $25.34 \pm 3.39$ & $25.12 \pm 3.36$ & $25.29 \pm 3.63$ & $25.67 \pm 2.48$ & 0.75 \\
\hline Smoker, \% & $140(63.2)$ & $22(15.7)$ & $97(69.2)$ & $21(15.0)$ & 0.45 \\
\hline Alcohol Consumption, $\%$ & $119(52.9)$ & $12(36.3)$ & $79(53.0)$ & $28(66.7)$ & 0.28 \\
\hline Low Occupational Position & $78(34.6)$ & $27(34.6)$ & $45(57.7)$ & $6(7.7)$ & 0.00 \\
\hline
\end{tabular}

To test the trend across education level, we used one-way ANOVA analysis for variables, Pearson chi-square tests comparing males and females for proportion taking anti-hypertensive medication, and proportion of current smokers and alcohol consumption (those reported moderate or heavy consumption). Low occupational position indicates unemployment or labor workers.

Table 2. Associations between educational attainment and blood pressure as well as conventional factors in linear analysis.

\begin{tabular}{ccccccc}
\hline & \multicolumn{5}{c}{ Educational Attainment (years) } \\
\hline Sex (n) & Age & SBP & DBP & Smoking & Alcohol consumption & Medication usage \\
\hline Female (277) & -0.08 & $-0.13^{*}$ & -0.04 & -0.09 & 0.07 & 0.03 \\
Male (225) & $-0.14^{*}$ & -0.09 & 0.01 & -0.09 & 0.11 & 0.13 \\
\hline
\end{tabular}

*Correlation is significant at the 0.05 level.

weak. Secondly, there is area bias as this result was obtained from a city community. It may not be generalized before multi-center research conducted for further testifies.

\section{Conclusion}

This study demonstrated that education is inversely associated with systolic blood pressure in female hypertensives, which adding evidence to the research of this kind in Chinese population.

\section{Acknowledgements}

This work was supported by the National Natural Science Foundation of China (No. 30771836) and Project for High-level Talents in Guangdong Higher Education (No. [2010]79).

\section{REFERENCES}

[1] M. A. Gonzalez, F. Rodriguez Artalejo, et al., "Relationship between Socioeconomic Status and Ischaemic Heart Disease in Cohort and Case Control Studies: 1960-1993," International Journal of Epidemiology, Vol. 27, No. 3, 1998, pp. 350-358. doi:10.1093/ije/27.3.350

[2] D. Gu, R. P. Wildman, X. Wu, et al., "Incidence and Predictors of Hypertension over 8 Years among Chinese Men and Women," Journal of Hypertension, Vol. 25, No. 3, 2007, pp. 517-523. doi:10.1097/HJH.0b013e328013e7f4

[3] E. B. Loucks, M. Abrahamowicz, Y. Xiao, et al., "Associations of Education with 30 Year Life Course Blood 
Pressure Trajectories: Framingham Offspring Study," BMC Public Health, Vol. 28, No. 11, 2011, p. 139.

[4] B. H. Strand and A. Tverdal, "Trends in Educational Inequalities in Cardiovascular Risk Factors: A Longitudinal Study among 48,000 Middle-Aged Norwegian Men and Women," European Journal of Epidemiology, Vol. 21, No. 10, 2006, pp. 731-739. doi:10.1007/s10654-006-9046-5

[5] M. Hukkinen, J. Kaprio, U. Broms, et al., "Characteristics and Consistency of Light Smoking: Long-Term FollowUp among Finnish Adults," Nicotine \& Tobacco Research, Vol. 11, 2009, pp. 797-805. doi:10.1093/ntr/ntp065

[6] M. T. Streppel, M. C. Ocké, H. C. Boshuizen, et al., "Long-Term Wine Consumption Is Related to Cardiovascular Mortality and Life Expectancy Independently of Moderate Alcohol Intake: The Zutphen Study," Journal of Epidemiology \& Community Health, Vol. 63, 2009, pp. 534-540. doi:10.1136/jech.2008.082198

[7] H. M. Colhoun, H. Hemingway and N. R. Poulter, "Socio-Economic Status and Blood Pressure: An Overview Analysis," Journal of Human Hypertension, Vol. 12, No. 2, 1998, pp. 91-110. doi:10.1038/sj.jhh.1000558

[8] A. Steptoe and G. Willemsen, "The Influence of Low Job Control on Ambulatory Blood Pressure and Perceived Stress over the Working Day in Men and Women from the Whitehall II Cohort," Journal of Hypertension, Vol.
22, No. 5, 2004, pp. 915-920. doi:10.1097/00004872-200405000-00012

[9] R. C. Thurston, L. D. Kubzansky, I. Kawachi, et al., "Is the Association between Socioeconomic Position and Coronary Heart Disease Stronger in Women than in Men?' American Journal of Epidemiology, Vol. 162, No. 1, 2005 , pp. 57-65. doi:10.1093/aje/kwi159

[10] A. Brännlund, A. Hammarström and M. Strandh, "Education and Health-Behaviour among Men and Women in Sweden: A 27-Year Prospective Cohort Study," Scandinavian Journal of Public Health, Vol. 41, No. 3, 2013, pp. 284-292. doi:10.1177/1403494813475531

[11] B. Williams, L. H. Lindholm and P. Sever, "Systolic Pressure Is All That Matters," Lancet, Vol. 371, No. 9631, 2008, pp. 2219-2221. doi:10.1016/S0140-6736(08)60804-1

[12] R. Hardy, D. Kuh, C. Langenberg and M. E. Wadsworth, "Birthweight, Childhood Social Class, and Change in Adult Blood Pressure in the 1946 British Birth Cohort," Lancet, Vol. 362, No. 9391, 2003, pp. 1178-1183. doi:10.1016/S0140-6736(03)14539-4

[13] A. P. van den Elzen, M. A. de Ridder, D. E. Grobbee, et al., "Families and the Natural History of Blood Pressure. A 27-Year Follow-Up Study," American Journal of Hypertension, Vol. 17, No. 10, 2004, pp. 936-940. doi:10.1016/S0895-7061(04)00871-4 